\title{
The prevalence and root causes of surgical site infections in public versus private hospitals in Ethiopia: a retrospective observational cohort study
}

\author{
Kidanie Fisha ${ }^{1}$, Muluken Azage ${ }^{2}$, Getasew Mulat ${ }^{3}$ and Koku Sisay Tamirat ${ }^{4^{*}}$
}

\begin{abstract}
Background: Healthcare-associated illnesses, of which surgical site infection is the most common are significant causes of morbidity and mortality. Therefore, this study aimed to determine the prevalence and root causes of surgical site infections in public versus private hospitals in Ethiopia.

Methods: An institution based retrospective observational cohort study was conducted among patients who underwent surgical procedures at public and private health facilities from March 15 to April 15, 2018. Samples were selected by the simple random sampling technique, and data extracted from the patient's medical chart, operation, and anesthesia notes. Data were entered using Epi info version 7 and analyzed using STATA 14. Binary logistic regression was fitted to identify factors associated with surgical site infections in private and public hospitals. Crude and adjusted odds ratios (OR) with a 95\% confidence interval (Cl) were computed to assess the strength of associations. Variables with a $p$-value less than 0.05 in the multivariable logistic regression model considered as significant predictors of surgical site infections.

Result: The overall prevalence of surgical site infections was $9.9 \%(95 \% \mathrm{Cl}: 7.8,12.5)$. The prevalence of the infections was higher in procedures performed in public hospitals (13.4\%) compared to private hospitals (6.5\%). Rural residence $(A O R=0.13,95 \% C l: 0.034$ 0.55), clean-contaminated and dirty wound ( $\mathrm{OOR}=12.81,95 \% \mathrm{Cl}: 4.42$ 37.08) were significant predictors of the infections in private hospitals. Similarly, clean-contaminated and dirty wounds (AOR $=4.37,95 \% \mathrm{Cl}: 1.88$ 10.14), length of hospital stay $\geq 6$ days ( $A O R=2.86,95 \% \mathrm{Cl}: 1.117 .33)$, and surgical operation time of over $1 \mathrm{~h}$ $(A O R=15.24,95 \% \mathrm{Cl}: 4.4851 .83)$ were such factors in public hospitals.

Conclusion: The prevalence of surgical site infections was high, and significant differences were also observed between public and private hospitals. Clean-contaminated and dirty wounds, prolonged operation, and length of hospital stay were predictors of surgical site infections among patients in public hospitals, whereas clean-contaminated wound and rural dwellings were predicted the infections among patients operated in the private hospital.
\end{abstract}

Keywords: Surgical site infection, Root causes, Private versus public hospital, Ethiopia

\footnotetext{
* Correspondence: kokusisay23@gmail.com

${ }^{4}$ Department of Epidemiology and Biostatistics Institute of Public Health,

College of Medicine and Health Science, University of Gondar, Gondar,

Ethiopia

Full list of author information is available at the end of the article
}

(C) The Author(s). 2019 Open Access This article is distributed under the terms of the Creative Commons Attribution 4.0 International License (http://creativecommons.org/licenses/by/4.0/), which permits unrestricted use, distribution, and reproduction in any medium, provided you give appropriate credit to the original author(s) and the source, provide a link to the Creative Commons license, and indicate if changes were made. The Creative Commons Public Domain Dedication waiver (http://creativecommons.org/publicdomain/zero/1.0/) applies to the data made available in this article, unless otherwise stated. 


\section{Background}

Healthcare-associated infections (HIAs) are a significant source of preventable morbidity and mortality [1-3]. More than $30 \%$ of the HIA are surgical site infections (SSI) defined as infections related to operative procedures that occur at or near surgical incisions within 30 days of the procedure or within 90 days if prosthetic materials are implanted at surgery [4]. Surgical site infections may extend from the skin and superficial subcutaneous tissues of incision sites to deep subcutaneous tissues and organ spaces [5]. Due to poor infection prevention practices among health care facilities in low and middle-income countries, the incidence of SSI is substantially higher than in high-income countries [6, 7].

SSI posed a significant clinical and financial burden on patients. Those who developed post operation SSI had 2-11 times higher risk of mortality [8]. Moreover, SSIs had a wide range of effects on patients and health care systems like; patient discomfort, prolonged hospital stay, and more days off work. In addition, SSI increased the cost of therapy, and the cost of an operation catastrophically raise by 300 to $400 \%[9,10]$.

Surgical site infections are attributable to a variety of factors which can be classified into patient-related, procedure-related and others. Other risk factors include the volume of surgeries performed in the department, the season, the working environment in the operation room, and the indications for surgery $[3,6,8,11]$. The World Health Organization (WHO) and other studies indicated that periodic surveillance and feedback for surgeons on SSIs rate and associated factors can decrease up to $50 \%$ of cases [12].

Government stakeholders such as the Federal Ministry of Health of Ethiopia (FMOH) and different health sector stakeholders incorporated surgical site infections with hospital key performance indicators (KPI) for continued surveillance of the conditions. Also, infection prevention and patient safety training and updates need to be continuously given to health care workers. Though some studies/clinical audits have been conducted in other subSaharan countries, there has been scarce evidence that compares the prevalence of surgical site infections between public and private hospitals in Ethiopia.

Therefore, our study aimed to determine the prevalence and root causes of surgical site infections in public versus private hospitals of Ethiopia. This study could provide insight into surgical site infections to different organizations and could help in evidence-based interventions in health facilities.

\section{Methods}

\section{Study design}

An institution based retrospective observational cohort study was carried out in public and private hospitals of
Bahir Dar city, Ethiopia, from March 15 to April 15, 2018. Bahir Dar is the capital city of the Amhara National Regional State, located $565 \mathrm{~km}$ northwest of Addis Ababa, Ethiopia. The city has two public and two private hospitals which serve the people in the city and nearby districts. Of the hospitals, Feleghiwot comprehensive specialized is public, and ADINAS and GAMBY are private hospitals included in the study. The public and private hospitals had a total of 436 and 69 beds, respectively with general surgical and orthopedics, gynecological and obstetric operation rooms. Twenty surgeons, 63 residents and general practitioners (GPs), 12 anesthetists, and 69 nurses worked in the surgical departments of the public and private hospitals. On average, more than 8,000 patients got admitted into the surgical, gynecology and orthopedic wards of the public hospitals each year. Similarly, more than 5,000 patients got surgical services in private hospitals annually.

\section{Patient population}

All patients admitted and underwent a surgical procedure in the public and private hospitals of the city were the source population. Patients who underwent elective and emergency major operations and admitted into the surgical, orthopedics, gynecology and obstetrics wards of the hospital during the study were included in the study. Patients who underwent re-operations and had contaminated and dirty operations, neonates and included patients who showed signs and symptoms of infection within $48 \mathrm{~h}$ of admission and patients admitted for less than $48 \mathrm{~h}$ were excluded from the study.

The sample size was determined using two population proportions with the assumptions of surgical site infection of $50 \%$ in the public and $38 \%$ in the private hospitals and $80 \%$ power with a 1:1 ratio. The final calculated sample size was 642 study participants (321 patients from each type). Initially, one public and two private hospitals were selected. Of the two public hospitals in the city only one of the public hospital that was Feleghiwote Comprehensive specialized public hospital selected with its 321 patients. This hospital is the referral site for the surgical procedure from lower health facilities and primary hospitals. Furthermore, Samples were proportionally assigned to the private hospitals accordingly to the number of patients operated on there. Thus, 158 and 163 patients were selected from ADINAS and GAMBY teaching hospitals, respectively. The final samples/patients were selected using the simple random sampling technique from hospital registration databases and operation logbooks.

\section{Data collection and analysis}

A pre-tested and structured questionnaire was used to collect data adopted from a variety of literature. Patient 
socio-demographic characteristics, clinical profiles and surgical procedure relating characteristics were collected from patient medical records and surgeons operation and anesthesia notes. Three clinical nurses and one supervisor were involved in the data collection process. The training was given for 1 day on how to select study participants and review medical documents. Before the actual data collection, the questionnaire was pre-tested in another hospital, appropriate corrections were made according to the findings. The research team supervised the data collection process daily.

Surgical site infection following surgical procedures was the outcome variable in both public and private hospitals. Socio-demographic variables (age, sex, residence, and average monthly income), clinical characteristics (wound type, ASA score, length of hospital stay, duration of surgical operation and the surgeon, comorbidities) were independent variables. Surgical site infection: An infection related to an operative procedure that occurs at or near the surgical incision within 30 days of the procedure or within 90 days if prosthetic material is implanted at the surgery.

The collected data were edited, coded and entered into Epi-info version 7 and export to SPSS version 20 software for further data management and analysis. Summary measures like percentage, means, and standard deviation were computed and the summarized data were presented in tables, graphs, and charts for both the private and public hospitals. A binary logistic regression model was fitted for overall and independently for the public and private hospitals to identify factors associated with surgical site infection. Crude and adjusted odds ratios (OR) with a $95 \% \mathrm{CI}$ were computed to assess the strength of association between the independent and outcome variable. Variables with a $p$-value of less than 0.05 were considered as statistically significant predictors of surgical site infections.

\section{Results}

\section{Socio-demographic characteristics}

A total of 642 patients who underwent surgical procedures were included (321 from each hospital). The median age of patients was 33 (IQR: 25-46) years; about $43.9 \%$ of them were aged $\geq 36$ years. More than half (54.2\%) of the patients in the public, $60.9 \%$ in private hospitals were female. Similarly, $54.5 \%$ in the public hospital and $70.1 \% \%$ in the private hospital were rural and urban dwellers, respectively (Table 1).

Elective surgery was the most common (64.5\%) procedure in the private and $59.85 \%$ in the public hospitals. Regarding chronic comorbidities $13.4 \%$ of participants had one or more co-morbidities of which DM, hypertension and HIV were the most common. Clean wound type was the most common (76.3\%) the in public and
Table 1 socio-demographic characteristics of clients among public and private hospital Bahir Dar Amhara Region, June 2018 $(n=642)$

\begin{tabular}{llll}
\hline Variable & $\begin{array}{l}\text { Public hospital } \\
\text { no }(\%) n=321\end{array}$ & $\begin{array}{l}\text { Private hospital } \\
\text { no }(\%) n=321\end{array}$ & $\begin{array}{l}\text { Total } \\
\text { no }(\%) n=642\end{array}$ \\
\hline $\begin{array}{l}\text { Age in years } \\
<=24\end{array}$ & $70(21.8 \%)$ & $76(23.67 \%)$ & $146(22.7 \%)$ \\
$25-35$ & $128(39.87 \%)$ & $86(26.79 \%)$ & $214(33.4 \%)$ \\
$>=36$ & $123(38.3 \%)$ & $159(49.5 \%)$ & $282(43.9 \%)$ \\
Monthly income (ETB) & & \\
$<=1600$ & $111(34.6 \%)$ & $60(18.7 \%)$ & $171(26.6 \%)$ \\
$1601-2500$ & $88(27.4 \%)$ & $79(24.6 \%)$ & $167(26.01 \%)$ \\
$>=2501$ & $122(38.0 \%)$ & $182(56.7 \%)$ & $304(47.35 \%)$ \\
Sex & & & \\
Male & $126(39.3 \%)$ & $147(45.8 \%)$ & $273(42.5 \%)$ \\
Female & $195(60.7 \%)$ & $174(54.2 \%)$ & $369(57.5 \%)$ \\
Residence & & & $371(57.78 \%)$ \\
Urban & $146(45.5 \%)$ & $225(70.1 \%)$ & $271(42.2 \%)$ \\
Rural & $175(54.5 \%)$ & $96(29.9 \%)$ & \\
\hline
\end{tabular}

$(88.2 \%)$ in the private hospitals. Abdominal laparotomy of which 33.3 and $55.7 \%$ were performed in the public and private hospitals, respectively was the most common procedure. The majority of the surgical procedures were done by surgeons in the private hospitals and residents and general practitioners in the public hospital, 98.4 and $71.1 \%$, respectively. Regarding the duration of surgical procedures, $58.88 \%$ operation in the public and $41.43 \%$ in the private hospitals lasted 30-60 min (Table 2).

\section{Prevalence of surgical site infections}

The overall prevalence of surgical site infections at both public and private hospitals was $9.9 \%$ with $(95 \% \mathrm{CI}$ : 7.8 to $12.5 \%)$. The prevalence of surgical site infection in the public hospital was $13.4 \%$ (95\%CI: $9.7-17.1 \%$ ) and 6.5\% (95\%CI: 4.0-9.3\%) in private hospitals.

\section{Factors associated with surgical site infection following procedures}

We fitted three different models to identify factors associated with surgical site infections in both and public versus private hospitals.

The first model was fitted to assess the overall factors of surgical site infection in all hospitals. Variables such as wound type, average monthly income, length of hospital stay, a physician who performed the procedure, and duration of procedure were significantly associated with surgical site infections in hospitals. Accordingly, for patients who had contaminated and dirty wounds, the odds of surgical site infections were 5.35 times higher compared to those who had clean wounds $[\mathrm{AOR}=5.35$, 95\%CI (2.84 10.06)]. Similarly, average monthly income 
Table 2 Clinical characteristics of patients undergone a surgical procedure in Bahir Dar city public and private hospitals, Ethiopia, June $2018(n=642)$

\begin{tabular}{|c|c|c|c|}
\hline Variable & $\begin{array}{l}\text { Public Hospital } \\
(N=321)\end{array}$ & Private Hospital $(N=321)$ & Total $(N=642)$ \\
\hline \multicolumn{4}{|l|}{ Type of surgery } \\
\hline Elective & $192(59.8 \%)$ & $207(64.5 \%)$ & $399(62.15 \%)$ \\
\hline Emergency & $129(40.2 \%)$ & $114(35.5 \%)$ & $243(37.85 \%)$ \\
\hline \multicolumn{4}{|l|}{ Given antibiotic prophylaxis } \\
\hline Yes & $305(95.0 \%)$ & $306(95.3 \%)$ & $611(95.2 \%)$ \\
\hline No & $16(5.0 \%)$ & $15(4.7 \%)$ & $31(4.8 \%)$ \\
\hline \multicolumn{4}{|c|}{ Timing of prophylactic drug administration } \\
\hline Before surgery & $305(95.0 \%)$ & $275(85.7 \%)$ & $580(90.39 \%)$ \\
\hline After surgery & $16(5.0 \%)$ & $46(14.3 \%)$ & $62(9.65 \%)$ \\
\hline \multicolumn{4}{|l|}{ ASA score } \\
\hline Class1 & $162(50.5 \%)$ & $301(93.8 \%)$ & $463(72.1 \%)$ \\
\hline Class2 & $132(41.1 \%)$ & $17(5.3 \%)$ & 149 (23.2\%) \\
\hline Class3 & $22(6.9 \%)$ & $3(0.9 \%)$ & $25(3.9 \%)$ \\
\hline Class4 & $5(1.6 \%)$ & 0 & $5(0.8 \%)$ \\
\hline \multicolumn{4}{|l|}{ Substance use } \\
\hline No & $305(95.0 \%)$ & $296(92.2 \%)$ & $601(93.6 \%)$ \\
\hline Yes & $16(5.0 \%)$ & $25(7.8 \%)$ & $41(6.4 \%)$ \\
\hline \multicolumn{4}{|l|}{ Types of substance use } \\
\hline Alcoholic & $4(1.2 \%)$ & $15(4.7 \%$ & $19(2.95 \%)$ \\
\hline Smoker & $12(3.8 \%)$ & $10(3.1)$ & $223.4 \%)$ \\
\hline \multicolumn{4}{|l|}{ Had co-morbidities } \\
\hline No & $270(84.1 \%)$ & $286(89.1 \%)$ & $556(86.6 \%)$ \\
\hline Yes & $51(15.9 \%)$ & $35(10.9 \%)$ & $86(13.39 \%)$ \\
\hline \multicolumn{4}{|l|}{ Type of co-morbidities } \\
\hline Diabetes mellitus & $10(3.1 \%)$ & $14(4.4 \%)$ & $24(3.7 \%)$ \\
\hline HIV & $8(2.5 \% 0$ & $6(1.9 \%)$ & $14(2.1 \%)$ \\
\hline Hypertension & $1(4.7 \%)$ & $11(3.4 \%)$ & $12(1.9 \%)$ \\
\hline Malignancy & $13(4.0 \%)$ & $9(2.850$ & $22(3.4 \%)$ \\
\hline \multicolumn{4}{|l|}{ Antiseptic used for skin preparation } \\
\hline lodine & $31(9.7 \%)$ & $20(6.2 \%)$ & $51(7.9 \%)$ \\
\hline Isopropyl alcohol I plus iodine & $237(73.8 \%)$ & $266(82.9 \%$ & $503(78.34 \%)$ \\
\hline Isopropyl alcohol & $53(16.5 \%)$ & 35 (10.9\%) & $88(13.7 \%)$ \\
\hline \multicolumn{4}{|l|}{ provider doing the procedure } \\
\hline Surgeon & 93 & 316 & 409 (63.7\%) \\
\hline Resident and GP & 228 & 5 & $233(36.3 \%)$ \\
\hline \multicolumn{4}{|l|}{ Type of surgery } \\
\hline Neuro surgery & $33(10.3 \%)$ & $32(10.0 \%)$ & 65 (10.12\%) \\
\hline Abdominal Surgery & $114(35.5 \%)$ & $179(55.8 \%)$ & $293(45.6 \%)$ \\
\hline Chest surgery & $23(7.2 \%)$ & $6(1.9 \%)$ & $29(4.5 \%)$ \\
\hline Genitourinary Surgery & $23(7.2 \%)$ & $31(9.75)$ & $54(8.4 \%)$ \\
\hline Cesarean section Surgery & 128 (39.9\%) & $73(22.7 \%)$ & $201(31.3 \%)$ \\
\hline \multicolumn{4}{|l|}{ Type of dressing } \\
\hline Gauze & 179 (55.8\%) & $33(10.3 \%)$ & 212 (33.02\%) \\
\hline
\end{tabular}


Table 2 Clinical characteristics of patients undergone a surgical procedure in Bahir Dar city public and private hospitals, Ethiopia, June 2018 ( $n=642)$ (Continued)

\begin{tabular}{|c|c|c|c|}
\hline Variable & $\begin{array}{l}\text { Public Hospital } \\
(N=321)\end{array}$ & Private Hospital $(N=321)$ & Total $(N=642)$ \\
\hline Gauze and saline & 79 (24.6\%) & $264(82.2 \%)$ & $343(53.4 \%)$ \\
\hline Gauze and lodine & $63(19.6 \%)$ & $24(7.5 \%)$ & $87(13.6 \%)$ \\
\hline \multicolumn{4}{|l|}{ Duration of operation } \\
\hline within 30 min & $75(23.36 \%)$ & $140(43.6 \%)$ & 215 (33.48\%) \\
\hline $31-60 \mathrm{~min}$ & 189 (58.87\%) & $133(41.43 \%)$ & $322(50.15 \%)$ \\
\hline$\geq 60 \mathrm{~min}$ & $57(17.76 \%)$ & $48(14.95 \%)$ & 105 (16.36) \\
\hline \multicolumn{4}{|l|}{ Wound type } \\
\hline Clean & $245(76.32 \%)$ & $242(75.38 \%)$ & $487(82.2 \%)$ \\
\hline Contaminated and dirty & $76(23.675)$ & $79(24.61 \%)$ & 155 (3.4\%) \\
\hline \multicolumn{4}{|l|}{ Length of stay at hospital } \\
\hline$<6$ days & $144(44.86 \%)$ & $190(59.19 \%$ & $334(52.02)$ \\
\hline$\geq 6$ days & $177(55.14)$ & $131(40.80 \%)$ & $308(47.98)$ \\
\hline \multicolumn{4}{|l|}{ Got blood transfusion } \\
\hline Yes & $26(8.10 \%)$ & $80(24.92 \%)$ & $106(16.51 \%)$ \\
\hline No & 295 (91.90\%) & $241(75.08 \%)$ & $536(83.49 \%)$ \\
\hline
\end{tabular}

of $[1601-2500$ ETB $(\mathrm{AOR}=2.88,95 \% \mathrm{CI}: 1.157 .18)$ or $\geq$ $2501 \mathrm{ETB}(\mathrm{AOR}=2.54,95 \% \mathrm{CI}: 1.055 .99)]$ and length of hospital stay $\geq 6$ days $(\mathrm{AOR}=1.96,95 \% \mathrm{CI}$ : 1.03 3.71) were more likely to result in surgical site infections compared to their counterparts. Furthermore, surgical operation duration of above $1 \mathrm{~h}(\mathrm{AOR}=5.36,95 \% \mathrm{CI}$ : 2.09 13.7) and procedures are done by residents and general practitioners $(\mathrm{AOR}=3.99,95 \% \mathrm{CI}: 2.017 .91$ ) were more likely to cause surgical site infections compared to their counterparts (Table 3 ).

The second model was fitted for patients who underwent a surgical procedure in public hospitals only. Accordingly, wound type, length of hospital stay and duration of operation were factors associated with surgical site infections in public hospitals at a $p$-value of 0.05 . Patients who had clean-contaminated and dirty wounds [AOR $=4.37$, 95\%CI (1.88 10.14), length of hospital stay $\geq 6$ days $(\mathrm{AOR}=2.86,95 \% \mathrm{CI}: 1.117 .33)$, and surgical operation lasting above $1 \mathrm{~h}(\mathrm{AOR}=15.24,95 \% \mathrm{CI}: 4.48$ $51.83)$ were more likely to end in surgical site infections compared to their counterparts (Table 4).

The third model was fitted for patients who underwent a surgical procedure in private hospitals only. Variables such as residence and wound type were factors associated with surgical site infections in the multivariable logistic regression analysis at a $p$-value of 0.05 . For patients who had clean-contaminated and dirty wounds, the odds of surgical site infections were 12.81 times higher compared to those who had clean wounds (AOR $=12.81,95 \% C I: 4.42$ 37.08). For rural dwellers, the odds of surgical site infections was decreased by $87 \%$ compared to urban residents $(\mathrm{AOR}=0.13,95 \% \mathrm{CI}: 0.034$ 0.55) (Table 5).

\section{Discussion}

This study revealed that the overall prevalence of surgical site infections in the hospitals was $9.9 \%$ with $(95 \% \mathrm{CI}$ : 7.8 12.4). This finding was consistent with those of studies conducted at Suhil (11.1\%) [13] and Asela (9.4\%) [14] and Feleghiwot hospitals of Ethiopia (9.4\%) [15] and at public hospitals in Tanzania (12\%) [8]. However, this finding was lower than that of a study conducted at Hawassa hospital, Ethiopia (19.1\%) [16], Gahanna (39\%) [17]), Nigeria $38.1 \%$ [18] and India $21.66 \%$ [19]. The possible explanations might be differences in health care systems and socio-demographic characteristics of patients. The other difference might be the study population; in Nigeria and India surgical site infection assessments were done on patients who underwent laparotomy (abdominal surgery) which might have led to the overestimation of the prevalence. Nearly one-third of our procedures were Cesarean sections which had a lower risk for surgical site infections.

This study also revealed that the magnitude of surgical site infections varied by being $13.4 \%$ in the public and $6.5 \%$ in private hospitals. The possible explanations might be that most (98.4\%) of the surgical operations in private hospitals were performed by senior surgeons, while only $28.97 \%$ of the patients in the public hospital were operated on by senior surgeons. Moreover, private hospitals are relatively clean and implement strict infection prevention strategies to increase patient satisfaction. 
Table 3 Binary logistic regression analysis to identify factors associated with surgical site infection from overall hospitals in Bahir Dar city, Ethiopia, May 2018( $n=642)$

\begin{tabular}{|c|c|c|c|c|}
\hline \multirow[t]{2}{*}{ Characteristics } & \multicolumn{2}{|c|}{ Surgical site infection } & \multirow[t]{2}{*}{$\operatorname{COR}(95 \% \mathrm{Cl})$} & \multirow[t]{2}{*}{$\mathrm{AOR}(95 \% \mathrm{Cl})$} \\
\hline & Yes & No & & \\
\hline \multicolumn{5}{|l|}{ Age of patient } \\
\hline$\leq 24$ & 7 & 139 & 1 & 1 \\
\hline $25-35$ & 14 & 200 & $1.39(0.543 .53)$ & $1.35(0.483 .77)$ \\
\hline$\geq 36$ & 43 & 239 & $3.57(1.568 .15)$ & $2.32(0.906 .59)$ \\
\hline \multicolumn{5}{|l|}{ Sex of patients } \\
\hline Male & 36 & 237 & 1 & 1 \\
\hline Female & 28 & 341 & $0.54(0.320 .91)$ & $0.59(0.321 .09)$ \\
\hline \multicolumn{5}{|l|}{ Wound type } \\
\hline Clean & 27 & 460 & 1 & 1 \\
\hline Clean-contaminated and dirty & 37 & 118 & 5.34 (3.12 9.12) & $5.35(2.8410 .06)^{*}$ \\
\hline \multicolumn{5}{|l|}{ Monthly income in ETB } \\
\hline$\leq 1600$ & 10 & 161 & 1 & 1 \\
\hline $1601-2500$ & 22 & 145 & $2.44(1.115 .33)$ & $2.88(1.157 .18)^{*}$ \\
\hline$\geq 2501$ & 32 & 272 & 1.89 (0.90 3.95) & $2.54(1.055 .99)^{*}$ \\
\hline \multicolumn{5}{|l|}{ Length of hospital stay } \\
\hline$<6$ days & 18 & 316 & 1 & 1 \\
\hline$\geq 6$ days & 46 & 262 & $3.08(1.745 .44)$ & $1.96(1.033 .71)^{*}$ \\
\hline \multicolumn{5}{|l|}{ Duration of surgical procedure } \\
\hline$\leq 30 \min$ & 9 & 206 & 1 & 1 \\
\hline $31-60 \mathrm{~min}$ & 28 & 294 & $2.17(1.0074 .71)$ & 1.21 (0.49 2.99) \\
\hline$>60 \min$ & 27 & 78 & $7.92(3.56$ 17.60) & $5.36(2.0913 .75)^{*}$ \\
\hline \multicolumn{5}{|l|}{ Procedure done by } \\
\hline Surgeon & 25 & 384 & 1 & 1 \\
\hline Residents and GP & 39 & 194 & $3.08(1.815 .25)$ & $3.99(2.017 .91)^{*}$ \\
\hline \multicolumn{5}{|l|}{ Co-morbidities } \\
\hline No & 49 & 507 & 1 & 1 \\
\hline Yes & 15 & 71 & $2.18(1.164 .10)$ & $1.31(0.62$ 2.77) \\
\hline
\end{tabular}

*Shows $P$-value less than 0.05

In contrast, public hospitals serve the population in substandard conditions with poor infection prevention practices due to high patient load.

In general, income level, wound type, length of hospital stay $\geq 6$ days, longer operation procedure duration and procedures done by residents and GPs were predictors of the overall surgical site infections. On another hand, clean-contaminated wound type, length of hospital stay, duration of operation procedures were factors with associated surgical site infections in procedures in public hospitals, whereas residence and wound type were predictors of SSI in private hospitals.

Average monthly income of between ETB 1601-2500 and more than 2500 was associated with an increased occurrence of surgical site infections. This might be so because individuals with high income are often associated with co-morbidities like DM which alter immunity and increase susceptibility to nosocomial infections. In our study, most patients $(82.55 \%)$ with chronic co-morbidities had income greater than ETB 1601.

Thus, for patients who came from rural areas and had surgical procedures in private hospitals, the odds of surgical site infections decreased compared to urban residents. This might be so because in the prevalence of co-comorbidities like Diabetes and HIV is lower in rural areas. Nearly two-thirds of the elective procedures done were on rural residents which decreased the occurrence of surgical site infections. In addition, practices such as bathing before procedures which decolonize microbes on the body might contribute to reduced occurrences of SSI [20].

Clean-contaminated and dirty wounds were more likely to be associated with surgical site infections in 
Table 4 Binary logistic regression analysis to identify factors associated with surgical site infection among patients who undergone surgical procedure in public hospital of Bahir Dar city, Ethiopia, May, 2018 $(n=321)$

\begin{tabular}{|c|c|c|c|c|}
\hline \multirow[t]{2}{*}{ Characteristics } & \multicolumn{2}{|l|}{ SSI } & \multirow[t]{2}{*}{ COR(95\%Cl) } & \multirow[t]{2}{*}{ AOR(95\% Cl) } \\
\hline & Yes & No & & \\
\hline \multicolumn{5}{|l|}{ Age in years } \\
\hline$\leq 24$ & 4 & 66 & 1 & 1 \\
\hline $25-35$ & 9 & 119 & $1.24(0.374 .20)$ & $1.33(0.355 .00)$ \\
\hline$\geq 36$ & 30 & 93 & $5.32(1.78$ 15.82) & $3.28(0.98$ 10.99) \\
\hline \multicolumn{5}{|l|}{ Sex } \\
\hline Male & 23 & 103 & 1 & 1 \\
\hline Female & 20 & 175 & $0.51(0.260 .97)$ & $0.86(0.361 .89)$ \\
\hline \multicolumn{5}{|l|}{ Wound type } \\
\hline Clean & 20 & 225 & 1 & 1 \\
\hline Clean contaminated and dirty & 23 & 53 & $4.88(2.499 .53)$ & $4.37(1.8810 .14)^{*}$ \\
\hline \multicolumn{5}{|l|}{ Monthly income in ETB } \\
\hline$\leq 1600$ & 9 & 102 & 1 & 1 \\
\hline $1601-2500$ & 15 & 73 & $2.32(0.965 .61)$ & $2.42(0.846 .90)$ \\
\hline$\geq 2501$ & 19 & 103 & $2.09(0.904 .83)$ & $2.18(0.825 .76)$ \\
\hline \multicolumn{5}{|l|}{ Length of hospital stay } \\
\hline$<6$ days & 7 & 137 & 1 & 1 \\
\hline$\geq 6$ days & 36 & 141 & $4.99(2.1511 .61)$ & $2.86(1.117 .33)^{*}$ \\
\hline \multicolumn{5}{|l|}{ Duration of surgical procedure } \\
\hline$\leq 30 \min$ & 5 & 70 & 1 & 1 \\
\hline $31-60 \mathrm{~min}$ & 17 & 172 & 1.38 (0.49 3.89) & $2.52(0.827 .79)$ \\
\hline$>60 \min$ & 21 & 36 & $8.16(2.8423 .45)$ & $15.24(4.4851 .83)^{*}$ \\
\hline
\end{tabular}

*Shows $P$-value less than 0.05

Table 5 Binary logistic regression analysis to identify factors associated with surgical site infection among patients who undergone surgical procedure in private hospitals of Bahir Dar city, Ethiopia, May, 2018( $n=321)$

\begin{tabular}{|c|c|c|c|c|}
\hline \multirow[t]{2}{*}{ Characteristics } & \multicolumn{2}{|l|}{ SSI } & \multirow[t]{2}{*}{$\operatorname{COR}(95 \% \mathrm{Cl})$} & \multirow[t]{2}{*}{$\mathrm{AOR}(95 \% \mathrm{Cl})$} \\
\hline & Yes & No & & \\
\hline \multicolumn{5}{|l|}{ Residence } \\
\hline Urban & 18 & 207 & 1 & 1 \\
\hline Rural & 3 & 93 & $0.37(0.101 .29)$ & $0.13(0.0340 .55)^{*}$ \\
\hline \multicolumn{5}{|l|}{ Sex } \\
\hline Male & 13 & 134 & 1 & 1 \\
\hline Female & 8 & 166 & $0.49(0.201 .23)$ & $0.40(0.141 .12)$ \\
\hline \multicolumn{5}{|l|}{ Wound type } \\
\hline Clean & 7 & 235 & 1 & 1 \\
\hline Clean contaminated and dirty & 14 & 65 & $7.23(2.8018 .65)$ & $12.81(4.4237 .08)^{*}$ \\
\hline \multicolumn{5}{|l|}{ Length of hospital stay } \\
\hline$<6$ days & 4 & 119 & 1 & 1 \\
\hline$\geq 6$ days & 17 & 181 & $2.79(0.918 .50)$ & $2.95(0.85$ 10.19) \\
\hline \multicolumn{5}{|l|}{ Duration of surgical procedure } \\
\hline$\leq 30 \min$ & 4 & 136 & 1 & 1 \\
\hline $31-60 \mathrm{~min}$ & 11 & 122 & 3.06 (0.95 9.87) & $2.08(0.587 .44)$ \\
\hline$>60 \min$ & 6 & 42 & 4.85 (1.30 18.03) & $3.37(0.8014 .20)$ \\
\hline
\end{tabular}

*Shows $P$-value less than 0.05 
private, public, and overall hospitals. This finding is supported by findings at Hawassa and Suhil hospitals of Ethiopia [13], St. Petersburg, Russian Federation [21], Cameroon [22] and Tanzania [23]. This might be due to the fact that dirty wounds have more probability of developing infections than clean wounds in similar care practices if there is contamination that might lead to infections.

A prolonged operation time that exceeds $1 \mathrm{~h}$ was associated with increased surgical site infections in both groups of hospitals This finding was consistent with previous studies [22, 24]. This might be due to the fact that prolonged operations lead to more exposure to environments which might increase the probability of contamination. In addition, prolonged operation time may increase leakage from adjacent organs.

Generally, prolonged hospital stay was associated with increased surgical site infections among patients who underwent surgical procedures. This finding was consistent and was supported by another study [12, 17, 19, 25, 26]. Longer hospital stay increased the risk of healthcareassociated nosocomial infections. This study also revealed that longer hospital stays at public hospitals were also associated with increased occurrences of surgical site infections. This might be because the public hospital was visited by a large number of patients accompanied by poor infection prevention practices. This led to increased occurrences of surgical site infections.

Surgical procedures performed by residents and general practitioners were associated with increased surgical site infections compared to procedures done by surgeons. This finding was concordant with results in Cameron [22, 27]. This could be due to the fact that surgical outcome depends on professional skills and experiences. Residents and general practitioners' limited experience and skills might have contributed to increased occurrences of complications, including surgical site infections.

This study shares the limitations of retrospective study designs that are secondary data sources which have considerable missing. Surgical site infection diagnosis was merely made by clinical manifestations which might have introduced bias that led to under or overestimations of conditions. In addition, microbiological isolations were not done for all surgical site infection, and that might have introduced bias in the ascertainment of outcomes.

\section{Conclusion}

The prevalence of surgical site infections was high, and a significant difference was observed between public and private hospitals. High average monthly income, clean-contaminated and dirty wounds, prolonged operations, hospital stays, and procedures are done by residents and general practitioners were associated with surgical site infections. Specifically, clean-contaminated and dirty wounds, prolonged operations and hospital stays were predictors of surgical site infections in public hospitals, whereas rural dwelling and clean-contaminated and dirty wound also predicted surgical site infections in private hospitals.

\section{Abbreviations}

AOR: Adjusted odds ratio; ASA: American society of anesthesiologist score; DM: Diabetes mellitus; ENT: Eye nose and throat; ETB: Ethiopia birr; HAl: Health care-associated infections: HIV: Human immune virus:

ICU: Intensive care unit; OPD: Outpatient department; OR: Operation room;

SPSS: Statistical package for social science; SSIs: Surgical site infections; Study US: The United States; WHO: World Health Organization

\section{Acknowledgments}

We would like to thank data collators, supervisors and study participants for their contributions made.

\section{Authors' contributions}

KF, MA, GM, and KST conceived the study, involved in the study design, data collection, and data analysis, drafted the manuscript and critically reviewed the manuscript. All authors read and approved the final version of the manuscript.

Funding

I did not receive external funding for this research.

Availability of data and materials

The datasets used during the current study are available from the corresponding author on reasonable request.

Ethics approval and consent to participate

Ethical approval was secured from the research and Ethics committee of, GAMBY Medical and Business College. After receiving a permission letter from the regional health bureau and other respected organizations, information on the purpose of the study, even the right not to participate was assured for the participants during informed verbal consent. Any information taken from the participants were kept confidential. We use codes rather than names of the participant while we were collecting the data.

Consent for publication

Not applicable as there is no image or other confidentiality related issues.

Competing interests

The authors declare that they have no competing interests.

\section{Author details}

${ }^{1}$ Feleghiwote Comprehensive Specialized Hospital, Bahir Dar, Ethiopia. ${ }^{2}$ School of Public Health College of Medicine and Health Sciences, Bahir Dar University, Bahir Dar, Ethiopia. ${ }^{3}$ Department of public health, GAMBY Medical and Business College, Bahir Dar, Ethiopia. ${ }^{4}$ Department of Epidemiology and Biostatistics Institute of Public Health, College of Medicine and Health Science, University of Gondar, Gondar, Ethiopia.

Received: 16 April 2019 Accepted: 2 July 2019

Published online: 10 July 2019

References

1. Hawn MT, et al. Surgical site infection prevention: time to move beyond the surgical care improvement program. Ann Surg. 2011;254(3):494-501.

2. Englesbe MJ, et al. A statewide assessment of surgical site infection following colectomy: the role of oral antibiotics. Ann Surg. 2010;252(3):514.

3. Berbari EF, et al. The Mayo prosthetic joint infection risk score: implication for surgical site infection reporting and risk stratification. Infect Control Hosp Epidemiol. 2012:33(8):774-81.

4. Allegranzi $\mathrm{B}$, et al. New $\mathrm{WHO}$ recommendations on preoperative measures for surgical site infection prevention: an evidence-based global perspective. Lancet Infect Dis. 2016;16(12):e276-87. 
5. Horan TC, et al. CDC definitions of nosocomial surgical site infections, 1992: a modification of CDC definitions of surgical wound infections. Am J Infect Control. 1992;20(5):271-4.

6. Parienti JJ, et al. Hand-rubbing with an aqueous alcoholic solution vs traditional surgical hand-scrubbing and 30-day surgical site infection rates: a randomized equivalence study. Jama. 2002;288(6):722-7.

7. Mangram AJ, et al. Guideline for prevention of surgical site infection, 1999. Am J Infect Control. 1999;27(2):97-134.

8. Mawalla $B$, et al. Predictors of surgical site infections among patients undergoing major surgery at Bugando medical Centre in Northwestern Tanzania. BMC Surg. 2011;11(1):21.

9. Zimlichman E, et al. Healthcare-associated infections: a meta-analysis of costs and financial impact on the US health care system. JAMA Intern Med. 2013;173(22):2039-46.

10. Jenks $P$, et al. Clinical and economic burden of surgical site infection (SSI) and predicted financial consequences of elimination of SSI from an English hospital. J Hosp Infect. 2014;86(1):24-33.

11. Urquhart $\mathrm{DM}$, et al. Incidence and risk factors for deep surgical site infection after primary total hip arthroplasty: a systematic review. J Arthroplast. 2010; 25(8):1216-1222. e3.

12. Berenguer $\mathrm{CM}$, et al. Improving surgical site infections: using National Surgical Quality Improvement Program data to institute surgical care improvement project protocols in improving surgical outcomes. J Am Coll Surg. 2010;210(5):737-41.

13. Weldu MG, et al. Magnitude and determinant factors of surgical site infection in Suhul hospital Tigrai, northern Ethiopia: a cross-sectional study. Surg Infect. 2018;19(7):684-90.

14. Mamo T, et al. Risk factors for surgical site infections in obstetrics: a retrospective study in an Ethiopian referral hospital. Patient Saf Surg. 2017;11(1):24.

15. Gedefaw $G$, et al. Factors associated with surgical site infection among women undergoing obstetrics surgery at Felegehiwot referral hospital, Bahir Dar, Northwest Ethiopia: a retrospective cross-sectional study. Saf Health. 2018:4(1):14

16. Wodajo S, Belayneh M, Gebremedhin S. Magnitude and factors associated with post-cesarean surgical site infection at Hawassa University teaching and referral hospital, southern Ethiopia: a cross-sectional study. Ethiop J Health Sci. 2017:27(3):283-90.

17. Labi A, et al. Multi-Centre point-prevalence survey of hospital-acquired infections in Ghana. J Hosp Infect. 2019:101(1):60-8.

18. Olowo-Okere A, et al. Prevalence of surgical site infection in a Nigerian University teaching hospital. J Pharm Allied Sci. 2017;14:2430-8,

19. Setty NK, Nagaraja MS, Nagappa DH, Giriyaiah CS, Gowda NR, Naik RD. A study on Surgical Site Infections (SSI) and associated factors in a government tertiary care teaching hospital in Mysore, Karnataka. Int J Med Public Health. 2014;4(2).

20. Webster J, Osborne S. Preoperative bathing or showering with skin antiseptics to prevent surgical site infection. Cochrane Database Syst Rev. 2015:(2):CD004985

21. Brown SM, et al. Prospective surveillance for surgical site infection in St. Petersburg, Russian Federation. Infect Control Hosp Epidemiol. 2007;28(3):319-25.

22. Cheng $\mathrm{H}$, et al. Prolonged operative duration increases risk of surgical site infections: a systematic review. Surg Infect. 2017;18(6):722-35.

23. Mpogoro FJ, et al. Incidence and predictors of surgical site infections following cesarean sections at Bugando medical Centre, Mwanza, Tanzania. Antimicrob Resist Infect Control. 2014;3(1):25.

24. Harrop JS, et al. Contributing factors to surgical site infections. J Am Acad Orthop Surg. 2012;20(2):94-101.

25. Kassin MT, et al. Risk factors for 30-day hospital readmission among general surgery patients. J Am Coll Surg. 2012;215(3):322-30.

26. Alp $E$, et al. Incidence and risk factors of surgical site infection in general surgery in a developing country. Surg Today. 2014:44(4):685-9.

27. Dhamecha, M., et al., Incidence \& Predictors of surgical site infections: a study at a tertiary care hospital. 2014.

\section{Publisher's Note}

Springer Nature remains neutral with regard to jurisdictional claims in published maps and institutional affiliations.

\section{Ready to submit your research? Choose BMC and benefit from:}

- fast, convenient online submission

- thorough peer review by experienced researchers in your field

- rapid publication on acceptance

- support for research data, including large and complex data types

- gold Open Access which fosters wider collaboration and increased citations

- maximum visibility for your research: over $100 \mathrm{M}$ website views per year

At $\mathrm{BMC}$, research is always in progress.

Learn more biomedcentral.com/submissions 